\title{
Ventilation Techniques and Risk for Transmission of Coronavirus Disease, Including COVID-19
}

\author{
A Living Systematic Review of Multiple Streams of Evidence
}

Holger J. Schünemann, MD, PhD, MSc; Joanne Khabsa, MPH*; Karla Solo, MSc*; Assem M. Khamis, MD;

Romina Brignardello-Petersen, DDM; Amena El-Harakeh, MPH; Andrea Darzi, MD, MPH; Anisa Hajizadeh, MPH;

Antonio Bognanni, MD; Anna Bak, PharmD; Ariel Izcovich, MD; Carlos A. Cuello-Garcia, MD, PhD; Chen Chen, MM;

Ewa Borowiack, MSc; Fatimah Chamseddine, MD; Finn Schünemann, MD; Gian Paolo Morgano, MSc;

Giovanna E.U. Muti-Schünemann, Cand. Med; Guang Chen, MD, PhD; Hong Zhao, PhD; Ignacio Neumann, MD, PhD; Jan Brozek, MD; Joel Schmidt, MD; Layal Hneiny, MPH, MLIS; Leila Harrison, MPH; Marge Reinap, MA; Mats Junek, MD; Nancy Santesso, PhD, MLIS; Rayane El-Khoury, MPH; Rebecca Thomas, MPH, MBChB; Robby Nieuwlaat, PhD; Rosa Stalteri, BSHc; Sally Yaacoub, MPH; Tamara Lotfi, MD, MPH; Tejan Baldeh, MPH; Thomas Piggott, MD, MSc; Yuan Zhang, PhD, MSc; Zahra Saad, MSc; Bram Rochwerg, MD, MSc; Dan Perri, MD; Eddy Fan, MD; Florian Stehling, MD; Imad Bou AkI, MD; Mark Loeb, MD, MSc; Paul Garner, MD; Stephen Aston, MD; Waleed Alhazzani, MD, MSc; Wojciech Szczeklik, MD; Derek K. Chu, MD, PhD; and Elie A. Akl, MD, MPH, PhD

Background: Mechanical ventilation is used to treat respiratory failure in coronavirus disease 2019 (COVID-19).

Purpose: To review multiple streams of evidence regarding the benefits and harms of ventilation techniques for coronavirus infections, including that causing COVID-19.

Data Sources: 21 standard, World Health Organization-specific and COVID-19-specific databases, without language restrictions, until 1 May 2020.

Study Selection: Studies of any design and language comparing different oxygenation approaches in patients with coronavirus infections, including severe acute respiratory syndrome (SARS) or Middle East respiratory syndrome (MERS), or with hypoxemic respiratory failure. Animal, mechanistic, laboratory, and preclinical evidence was gathered regarding aerosol dispersion of coronavirus. Studies evaluating risk for virus transmission to health care workers from aerosol-generating procedures (AGPs) were included.

Data Extraction: Independent and duplicate screening, data abstraction, and risk-of-bias assessment (GRADE for certainty of evidence and AMSTAR 2 for included systematic reviews).

Data Synthesis: 123 studies were eligible (45 on COVID-19, 70 on SARS, 8 on MERS), but only 5 studies (1 on COVID-19, 3 on SARS, 1 on MERS) adjusted for important confounders. A study in hospitalized patients with COVID-19 reported slightly higher mortality with noninvasive ventilation (NIV) than with invasive mechanical ventilation (IMV), but 2 opposing studies, 1 in patients with MERS and 1 in patients with SARS, suggest a reduction in mortality with NIV (very-low-certainty evidence). Two studies in patients with SARS report a reduction in mortality with NIV compared with no mechanical ventilation (low-certainty evidence). Two systematic reviews suggest a large reduction in mortality with NIV compared with conventional oxygen therapy. Other included studies suggest increased odds of transmission from AGPs.

Limitation: Direct studies in COVID-19 are limited and poorly reported.

Conclusion: Indirect and low-certainty evidence suggests that use of NIV, similar to IMV, probably reduces mortality but may increase the risk for transmission of COVID-19 to health care workers.

Primary Funding Source: World Health Organization. (PROSPERO: CRD42020178187)

Ann Intern Med. 2020;173:xxx-xxx. doi:10.7326/M20-2306 Annals.org For author, article, and disclosure information, see end of text

This article was published at Annals.org on 22 May 2020.

* Ms. Khabsa and Ms. Solo contributed equally.
A s of 18 May 2020, the ongoing pandemic caused by severe acute respiratory syndrome coronavirus 2 (SARS-CoV-2) has affected more than 4.8 million individuals worldwide and caused over 300000 deaths (1). SARS-CoV-2 spreads from person to person through close contact and causes coronavirus disease 2019 (COVID-19); most deaths are caused by development of hypoxemic respiratory failure and severe acute respiratory distress syndrome (ARDS).

Noninvasive ventilation (NIV), invasive mechanical ventilation (IMV), and supportive therapies are the mainstays of treatment of ARDS. Noninvasive ventilation is associated with fewer adverse outcomes for patients than is IMV. However, NIV creates risks for the health care workers ( $\mathrm{HCWs}$ ) caring for these patients, because of SARS-CoV-2 transmission via aerosols (2).
The magnitude of this risk is not well explored in COVID-19. In contrast, IMV typically uses a closed system and thus carries a much lower risk for transmission via aerosols. Countries with a large number of patients with COVID-19 requiring mechanical ventilation have experienced shortage of ventilators and have relied on NIV, which includes continuous positive airway pressure (CPAP), bilevel positive airway pressure (BiPAP), and high-flow oxygen by nasal cannula (HFNC). Guide-

See also:

Web-Only

Supplement 
lines vary considerably in their recommendations on the role and optimal method of NIV, reflecting differences in assumed effectiveness balanced with the risk for infection to HCWs from aerosols.

Hypoxemic respiratory failure and ARDS are common in COVID-19, but the ideal way of providing ventilation and the effect of NIV on HCWs is uncertain. Although they are different from other causes of ARDS, severe acute respiratory syndrome (caused by SARSCoV-1) or Middle East respiratory syndrome (caused by MERS-CoV) may resemble ARDS in $\operatorname{COVID-19}(3,4)$. Thus, evidence from SARS and MERS may be useful to explore the effects of NIV.

Commissioned by the World Health Organization (WHO) to inform their guidance documents, we urgently but systematically reviewed evidence to assess the benefits and harms of alternate noninvasive and invasive ventilation strategies in acute hypoxemic respiratory failure in patients with COVID-19. This included searching for indirect evidence (for example, that related to SARS and MERS) and for evidence on the effect of virus transmission on HCWs.

\section{MeTHODS}

By agreement with WHO on 3 April 2020, we performed an urgent systematic review to compare the effect of different ventilation techniques on important patient outcomes and the risk for transmission for coronavirus disease, including COVID-19. We adhered to Cochrane systematic review methods, rated the certainty of evidence by following the GRADE (Grading of Recommendations Assessment, Development and Evaluation) approach, prospectively registered the review on PROSPERO (registration number CRD42020178187) (Supplement 1, available at Annals.org), and followed PRISMA (Preferred Reporting Items for Systematic reviews and Meta-Analyses) reporting guidelines (5-9). We assembled a large international collaborative team of researchers, frontline and specialist clinicians, epidemiologists, patients, public health experts, and health policy experts with expertise in systematic reviews. The review addresses the following 4 streams of evidence: 1) studies of any design that addressed NIV for individuals with acute hypoxic respiratory failure caused by coronavirus (COVID-19, MERS, SARS); 2) systematic reviews of randomized trials that assessed the efficacy of NIV approaches in patients with hypoxemic respiratory failure not due to coronavirus infection; 3) animal, mechanistic, laboratory, and preclinical evidence regarding aerosol dispersion of coronavirus; and 4) studies in adults evaluating risk for virus transmission to $\mathrm{HCW}$ from aerosolgenerating procedures (AGPs). When possible, results focus on information most relevant to SARS-CoV-2 and COVID-19. Information related to the first stream of evidence will be continually updated and maintained as a living systematic review for at least 1 year.

\section{Data Sources and Searches}

Without language restrictions, we searched MEDLINE (by using the OVID platform); PubMed; EMBASE; Cl-
NAHL (by using the EBSCO platform); the Cochrane Library; the COVID-19 Open Research Dataset, hosted by Kaggle and created by the Allen Institute and collaborators; the COVID-19 Research Database maintained by the $\mathrm{WHO}$; Epistemonikos (by using its COVID-19 L.OVE [Living Overview of the Evidence] platform); the EPPI Centre's living systematic map of the evidence on COVID-19; ClinicalTrials.gov, the U.S. National Library of Medicine's register of clinical trials; and the WHO International Clinical Trials Registry Platform (Supplement 2, available at Annals.org). We also searched relevant documents on the websites of governmental and other relevant organizations and reference lists of the included papers and relevant systematic reviews. We also hand-searched preprint servers (bioRxiv, medRxiv, and preprints in The Lancet, part of Social Science Research Network First Look). Finally, we searched Chinese databases, including the WHO Chinese database, the China Biomedical Literature Service (SinoMed), the Chinese Scientific Journal Database (VIP), the Wanfang database, and the China National Knowledge Infrastructure (CNKI), until 1 May 2020 (Supplement 2).

The strategies combined Medical Subject Headings and keywords related to COVID-19, NIV, and IMV, as well as studies focusing on laboratory evidence related to virus spread via AGPs for the 4 streams described above. We developed separate search strategies for streams 1 (from 1 January 2002 to 1 May 2020), 2 (from 2017 to 1 May 2020), and 3 (inception to 1 May 2020) with a senior information specialist. We used the original search strategy (from inception to 2010) for stream 4 from a review by the Canadian Agency for Drugs and Technologies in Health (CADTH) (restricted to the MEDLINE and EMBASE databases and SARS-CoV-1, SARS-CoV-2, and MERSCoV until 1 May 2020) (2).

\section{Study Selection}

We included records addressing the following population, interventions, comparisons, outcomes, and study designs.

\section{Population}

We sought studies on patients with confirmed or probable COVID-19 infection and hypoxemic respiratory failure. We planned to evaluate different subgroups (Supplement 1), including different age groups and patients with comorbidities.

\section{Interventions}

Eligible interventions included NIV, including $\mathrm{Bi}$ PAP, CPAP, and HFNC; IMV via endotracheal tubes or tracheostomy; standard oxygen therapy; or no mechanical ventilation. We determined a priori to evaluate different types of interfaces (helmet, oronasal, or fullface mask). 


\section{Outcomes}

Outcomes of interest were death, transmission of COVID-19 to HCWs and other people, length of hospital and intensive care unit stay, complications of therapy, secondary bacterial pneumonia, need for invasive ventilation, need for tracheostomy, time to recovery from COVID-19, aerosol generation and droplet dispersion of live virus at various distances and times, and contextual outcomes (acceptability, feasibility, resources use, effect on equity).

\section{Study Designs}

Stream 1 consisted of studies of NIV in people with any acute hypoxic respiratory failure caused by coronavirus (COVID-19, MERS, or SARS). Evidence was prioritized by study design addressing the question of interest as follows: 1) randomized controlled trials (RCTs); 2) nonrandomized comparative studies; 3) noncomparative studies (that is, case series); and 4) qualitative studies (for contextual outcomes). We excluded single case reports.

Stream 2 consisted of systematic reviews published in 2017 or later that synthesized randomized trial evidence from patients with acute hypoxic respiratory failure who were critically ill but had neither suspected or confirmed COVID-19, MERS, or SARS. We included only recent credible systematic reviews (assessed by using AMSTAR 2 [A Measurement Tool to Assess Systematic Reviews 2]) because we intended to focus on up-to-date indirect evidence, and older reviews would not have included the most recent studies. We summarized the results of those reviews that are most credible (moderate- or high-quality rating on AMSTAR 2).

In streams 3 and 4, to identify all evidence about the risk for transmission of SARS-CoV-2 through AGPs, we evaluated additional streams of evidence. In stream 3, we selected controlled studies (animal, human, mechanistic, laboratory, preclinical, and simulation, among others) evaluating aerosol dispersion to inform the evidence about transmission of virus in confirmed cases of COVID-19, MERS, or SARS. We focused on COVID-19 in summarizing evidence, but if that evidence was sparse, we decided a priori to summarize evidence for MERS and SARS. For stream 4, we included all primary studies dealing with SARS, MERS, or COVID-19 published after 22 October 2010 (date of prior search) (2). This update focused on transmission of virus.

For all 4 streams, the reviewers pilot-tested a standardized title and abstract screening form by using the same citations. We then conducted calibration exercises by webinars for each stream. Once the form was calibrated, pairs of reviewers screened in duplicate and independently all titles and abstracts by using the eligibility criteria. Conflicts between reviewers were resolved by consensus or by a senior methodologist (H.J.S., D.C., E.A.A.). Reviewers pilot-tested a full-text screening form and participated in a webinar using the same 5 or more full-text articles. Once the form was calibrated, the pairs of reviewers screened the full texts independently and in duplicate and resolved any conflicts by discussion, or with the help of a senior methodologist (H.J.S., D.C., E.A.A.). We recorded the primary reason for exclusion at the full-text screening stage.

\section{Data Extraction and Risk-of-Bias Assessment}

For each of the 4 streams, we developed a standardized data abstraction form in Microsoft Excel and piloted it as part of calibration exercises with all reviewers. Teams of 2 reviewers extracted data in duplicate and independently; all extracted data were verified by 2 biostatisticians (A.K. and R.B.) and a senior reviewer (H.J.S., D.C., or E.A.A.). We extracted data on the following variables: study identifier; study design; setting; population, intervention, and comparator characteristics; outcomes (quantitative, if possible); source of funding and reported conflicts of interest; ethical approval; and study limitations or other important comments.

Two experienced reviewers performed the risk-ofbias assessment, and a senior methodologist (H.J.S. or E.A.A.) verified all assessments. We used the Newcastle-Ottawa Scale for nonrandomized studies $(10,11)$ and Cochrane Risk of Bias tool, version 2.0, for randomized trials (12). We assessed systematic reviews by using the AMSTAR 2 tool (13). We did not assess the risk of bias for studies identified in stream 3 .

\section{Data Synthesis and Analysis}

We synthesized the data in both narrative and tabular formats. One reviewer (H.J.S.) graded the certainty of the evidence by using the GRADE approach, and 2 senior reviewers (R.B. and E.A.A.) verified all assessments. When applicable, we followed published guidance for rating the certainty in evidence in the absence of a single estimate of effect $(14,15)$. We used the GRADEpro (www.gradepro.org) app to rate the evidence and present it in GRADE evidence profiles and summary of findings tables $(16,17)$ using standardized terminology $(18,19)$.

For quantitative analyses, we only included comparative studies-those that allowed a comparison of at least 2 interventions on an outcome of interest-in our synthesis. Although we planned meta-analyses, most studies provided unadjusted data or data that could not be combined in a meta-analysis. We therefore did not perform a meta-analysis and present raw numbers. We present adjusted odds ratios (ORs) when studies reported them, using RevMan (Cochrane).

\section{Living Review and Literature Surveillance}

We plan weekly literature surveillance through May 2021 for studies related to stream 1. This surveillance and updating will focus on studies in patients with COVID-19. We will use the search strategy for stream 1 (Supplement 1) and the selection, data abstraction, and quality and certainty assessment methods described above. We plan monthly updates or alerts that present search findings and describe new evidence. If substantive new literature emerges that changes our overall conclusions, changes the certainty of evidence (20), 
Figure 1. Mortality with NIV versus IMV.

Study, Year (Reference)

Alraddadi et al, 2019 (21): adjusted odds ratio, MERS

Wang et al, 2020 (29): hazard ratio, COVID-19

Yam et al, 2005 (31): adjusted odds ratio, SARS

Total $(95 \% \mathrm{Cl})$

Heterogeneity, $\tau^{2}=0.17 ; \chi^{2}=1.60(P=0.21) ; I^{2}=38 \%$

Test for overall effect: $Z=1.96(P=0.05)$ $\log$ [Odds Ratio] SE Weight

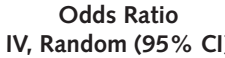

$\begin{array}{rrr}-0.494 & 0.495 & 54.3 \% \\ 0 & 0 & \\ -1.448 & 0.569 & 45.7 \%\end{array}$

$100.0 \%$
IV, Random ( $95 \% \mathrm{Cl}$ )

Odds Ratio

IV, Random ( $95 \% \mathrm{Cl}$ )

$0.61(0.23-1.61)$
Not estimable
$0.24(0.08-0.72)$

$0.39(0.16-1.00)$

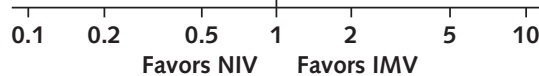

Three studies $(21,29,31)$ comparing NIV with IMV suggested both an increase and a reduction in mortality. COVID-19 = coronavirus disease 2019; IMV = invasive mechanical ventilation; IV = inverse variance; MERS = Middle East respiratory syndrome; NIV = noninvasive ventilation; SARS = severe acute respiratory syndrome.

provides data on additional outcomes, or provides data that would be appropriate for meta-analysis with other studies, we plan submission of an updated manuscript.

\section{Role of the Funding Source}

This systematic review was commissioned by the WHO on 3 April 2020. The WHO helped define the scope of the question but otherwise had no role in study design, data collection, data analysis, data interpretation, or writing of the report or the decision to submit it for publication.

\section{RESULTS}

\section{Stream 1: Systematic Review of Ventilation Strategies in Patients With Hypoxemic Respiratory Failure Due to Coronavirus Infection}

Among 38942 records, 123 studies were eligible (45 on COVID-19, 70 on SARS, 8 on MERS) in stream 1. Supplement 3 (available at Annals.org) shows the PRISMA flow diagram. Of these, 121 studies did not provide adequate data for extraction-for example, because outcome data could not be attributed to a specific treatment group. Supplement 4 (available at Annals.org) shows a description of these studies. Of the remaining 28 studies (11 on COVID-19, 15 on SARS, 2 on MERS) that had data for extraction (12, 21-47), 18 included NIV as a treatment of choice (Supplement 5, available at Annals.org). Only 5 studies (including 1 very small RCT) provided results that we judged as adequately adjusted for important confounders, such as comorbidities or severity of hypoxemia (3 on SARS, 1 on COVID-19, and 1 on MERS) (12, 21, 29, 31, 32). We considered the remaining 23 unadjusted studies as providing results at high risk of bias. This included the 10 studies in patients with COVID-19 that reported unadjusted results.

We judged the risk of bias (Supplement 4 and Supplement 5) as low for the cohort designs on the basis of the Newcastle-Ottawa Scale, but in our GRADE assessment, we accounted for the risks of selection and confounding bias due to the nonrandomized design, and we noted some concerns for the RCT. We judged the 23 unadjusted studies, including all COVID-19 studies, to be at moderate to high risk of bias because any es- timate of effect will be subject to strong confounding and selection bias. Furthermore, we identified studies for which there was no clear comparison, mostly defined as case series or case reports, which were generally at high risk of bias (Supplement 5).

Supplement 6 (available at Annals.org) shows the results of the studies with extractable data. Five studies reported adjusted results, one of them in patients with COVID-19. In these latter studies, 3 studies compared NIV with IMV and 2 studies compared NIV with no mechanical ventilation. The respective results from the former 3 studies (Figure 1) differ and suggest an imprecise increase in mortality in NIV compared with IMV in 1 study (COVID-19: hazard ratio, $1.61[95 \% \mathrm{Cl}, 0.84$ to 3.09]) and a reduction in mortality in 2 studies (MERS and SARS: OR, $0.61[\mathrm{Cl}, 0.23$ to 1.6$]$ and $0.24[\mathrm{Cl}, 0.10$ to 0.72$]$, respectively) (very low certainty of the evidence secondary to the nonrandomized study designs and concerns about inconsistency) (21, 29, 31). We were unable to perform a meta-analysis because of differences in how authors reported the effect estimates. For NIV compared with no mechanical ventilation, the RCT (32) suggested a reduction in mortality, but there were only 3 events in 60 patients in total, causing imprecision, and the nonrandomized study by $\mathrm{Xu}$ and colleagues (12) also showed a reduction in mortality (OR, $0.21[\mathrm{Cl}, 0.09$ to 0.47$]$; low certainty, owing to very serious imprecision of the RCT and the nonrandomized study design of the other study) (Figure 2).

The 10 additional studies in COVID-19 presented only unadjusted results. In the only study from Italy, Duca and associates (25) reported a higher death rate in patients receiving helmet CPAP or other NIV compared with IMV. For the 3 studies from China, Liao and coworkers (28) reported rates of recovery greater than $40 \%$ after 28 days of follow-up in patients who received NIV, HFNC, and conventional oxygen therapy. Wang and colleagues (29) found low rates of the need for IMV in patients receiving NIV or HFNC. Mortality was greater than $60 \%$ in the NIV group and was $100 \%$ in the IMV group in the study by Wu and associates (30). We did not calculate effect estimates for these latter studies, given the high risk for confounding and selection bias as well as other potential biases in these studies. We found only 1 study on contextual factors, which re- 
ported a 2.5-fold higher cost for patients with SARS treated with mechanical versus no mechanical ventilation from 2004. We found no studies that provided information on any of the contextual factors for decision making about NIV in COVID-19.

\section{Stream 2: Overview of Systematic Reviews of Randomized Trials That Assessed the Efficacy of NIV Approaches in Patients With Hypoxemic Respiratory Failure Not Due to Coronavirus Infection}

We identified 12 systematic reviews of indirect study populations that were judged to be credible on the basis of assessment with the AMSTAR 2 instrument (rating of moderate or high quality). Supplement 7 (available at Annals.org) provides the full ratings, and Supplement 3 shows the PRISMA flow chart. Consultation with our 7 content experts who are involved in care of patients with hypoxemic respiratory failure, including those with COVID-19, identified no additional systematic review that would have superseded the identified reviews, but 5 of these reviews included study populations that we judged as too indirect on final review (4852)-for example, because they were studies in postsurgery patients or those with cardiogenic pulmonary edema only (Supplement 7). We found no systematic review comparing IMV with NIV. We found no studies allowing us to draw conclusions about the indirect comparative efficacy of CPAP or BiPAP in COVID-19.

Two systematic reviews $(53,54)$ concluded that RCTs suggest a large reduction in mortality of NIV compared with conventional oxygen therapy for acute hypoxemic respiratory failure (Supplement 7 ). We included 4 systematic reviews of RCTs that compared HFNC, which is considered an NIV strategy by many content experts, with conventional oxygen therapy for adults (55-58) and 1 in children (59). The results overall suggested no reduction in mortality but a reduction in the need for IMV with the administration of HFNC. Compared with other NIV, 2 of the reviews of RCTs in adults $(56,57)$ suggested that HFNC had no effect on mortality or escalation of ventilatory support, including the need for intubation. The RCTs included in 1 review suggested that helmets are at least as efficacious as the use of facemasks in NIV (53). In children, the risk for treatment failure and mortality appeared to be in- creased with HFNC compared with CPAP (59) (Supplement 7).

\section{Stream 3: Systematic Review of Mechanistic, Animal, Human, Foundational Science, Preclinical, and Other Studies Describing the Risk for Transmission From AGPs}

To determine the risk for transmission of COVID19, we conducted a systematic review of mechanistic animal, human, preclinical, laboratory, and other studies and identified 25102 citations; Supplement 3 shows the PRISMA flow chart for the included studies. We included 6 studies assessing the presence or transmission of the 3 coronaviruses in different environments: MERS-CoV (2 studies) $(60,61)$, SARS-CoV (1 study) (62), and SARS-CoV-2/COVID-19 (3 studies) (6365). Wan and colleagues (62) studied droplet distribution of SARS-CoV when patients with SARS used a humidifier or a large-volume nebulizer and found that none of the air samples had SARS-CoV-specific DNA products. One study found that SARS-CoV-2 persisted up to 16 hours in airborne form (64), and another reported a higher rate of SARS-CoV-2 detection in the intensive care setting where patients were ventilated (67\% of air outlet swab samples and $44 \%$ of swab surface samples) (65). Adhikari and coworkers (60) modeled the transmission of MERS-CoV to HCWs visiting an index patient, other patients sharing the same room, and family visitors. The risk was highest among HCWs and mostly depended on the concentration of MERS$\mathrm{CoV}$ in the saliva. Pyankov and associates (61) used a virus-containing suspension aerosolized to an experimental aerosol chamber to compare, under controlled laboratory conditions, particle size and viable concentration of MERS-CoV in 2 different environments. They found higher evaporation and lower survival under hot and dry climatic conditions. Similarly, Bae and colleagues (63) found that coughing induces dissemination of SARS-CoV-2 and masks did not prevent colonization at a distance of $20 \mathrm{~cm}$.

\section{Stream 4: Update of Systematic Reviews of Human Studies Evaluating the Effect of AGPs}

In 2011, CADTH produced a rapid response report that systematically reviewed the risk for transmission of acute respiratory infection to $\mathrm{HCW}$ s exposed to pa-

Figure 2. Mortality with NIV compared with no MV.

Study, Year (Reference)

Liu, 2004 (32): SARS, RCT

Xu et al, 2010 (12): MERS, NRS, adjusted $\log [$ Odds Ratio]

$\begin{array}{rr}-2.04 & 1.42 \\ -1.57 & 0.411\end{array}$
Odds Ratio

IV, Random (95\% CI)

$0.13(0.01-2.10)$

$0.21(0.09-0.47)$

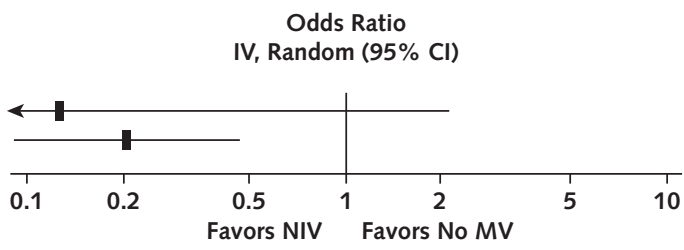

Odds Ratio

One RCT (32) suggests a reduction in mortality, but there were only 3 events in 60 patients in total, causing imprecision. The nonrandomized study by $\mathrm{Xu}$ and colleagues (12) showed a reduction in mortality. IV = inverse variance; MERS = Middle East respiratory syndrome; MV = mechanical ventilation; $\mathrm{NIV}=$ noninvasive ventilation; $\mathrm{NRS}=$ nonrandomized study; $\mathrm{RCT}=$ randomized controlled trial; SARS = severe acute respiratory syndrome. 
tients undergoing AGPs (2). The review included 5 case-control studies and 5 cohort studies evaluating the risk for SARS transmission to HCWs during AGPs (Supplements 8, 9, and 10, available at Annals.org). Only 4 of these studies provided adjusted effect estimates. The studies found large increases in the odds of SARS-CoV infection among HCWs performing or being present during tracheal intubation, or in $\mathrm{HCW}$ s performing chest compressions (66-69). Unadjusted studies reported an increased risk for transmission with tracheal intubation, NIV, manipulation of a BiPAP mask, and manual ventilation before intubation. Other AGPs were not associated with transmission in that report: endotracheal aspiration, suction of body fluids, bronchoscopy, nebulizer treatment, administration of oxygen, high-flow oxygen, defibrillation, insertion of nasogastric tube, and collection of sputum (Supplement 11, available at Annals.org).

Our update of this review identified 15 new studies (6 on COVID-19 and 9 on MERS), but these studies had high risk of bias (Supplement 12 and 13, available at Annals.org; Supplement 3 shows the PRISMA flow diagram). Most studies used real-time polymerase chain reaction to ascertain presence of virus. Three studies found no cases of transmission to HCWs in the following AGPs: bronchoscope-guided endotracheal intubation through nasal insertion (70); tracheostomy (71); endotracheal intubation, extubation, or NIV; and exposure to aerosols in an open circuit (72). Two additional studies reported no important association between the proportions of HCWs contracting acute respiratory illness in high-risk exposure versus other exposure in COVID-19 $(73,74)$, but another found that being present during or assisting with AGPs (nebulizer treatment or BiPAP) was more common among HCWs with COVID-19 (75). One study found an $11 \%$ infection rate among anesthetists who had direct contact with patients with COVID-19 who received oxygen via nasal cannula (76). Hall and colleagues (77) reported no infection among $\mathrm{HCW}$ s reporting contact with patients with MERS-CoV, although a proportion of them had been present during AGPs (airway suction, nebulizer treatment, sputum induction, bronchoscopy, and intubation). Alraddadi and associates (78) reported different rates of infection among HCWs in direct contact with patients and among those performing AGPs, and 2 case reports (79, 80) described infection with MERS-CoV after being present at cardiac resuscitations and having face-toface contact with a febrile HCW. However, these findings need to be interpreted with great caution, owing to a probable confounding effect of personal protective equipment (PPE) use and variable methods and reporting (81-84).

\section{Discussion}

This systematic review evaluating different ventilation strategies identified 28 original comparative studies in patients with SARS, MERS, and COVID-19. Although an additional 34 studies in patients with COVID-19 were found, their methods and reporting were too poor for us to synthesize data appropriately. Together, the indirect evidence, including 7 systematic reviews in other populations, suggests that NIV may reduce mortality or need for IMV, with similar effects to IMV. However, the use of NIV and the choice of the ventilation strategy must be balanced against the potentially increased risk for infection of HCWs resulting from these AGPs. One study in patients with COVID-19 that used CPAP with helmets, and RCTs included in 1 systematic review, suggested that helmets are at least as efficacious as masks in NIV $(25,54,85)$, and they have been used in children (86). Very limited evidence suggests that helmets may reduce the risk for transmission. Two additional comprehensive searches identified evidence that suggests a risk for infection for HCWs with COVID-19, SARS, and MERS (2). Tables 1 and 2 provide GRADE evidence profiles for 2 key comparisons (NIV versus IMV and NIV versus no mechanical ventilation), synthesizing the evidence and rating the certainty across the different streams for the most direct evidence (COVID-19, SARS, and MERS). Overall, the certainty of evidence is very low to low based on the observational design, which raises concerns about risk of bias. We did not rate down the evidence from patients with SARS or MERS for indirectness, because these diseases are caused by viruses belonging to the same family and subtype as SARS-CoV-2.

We are not aware of systematic reviews on the best NIV strategies in patients with COVID-19 who have acute hypoxemic respiratory failure. The adherence to full systematic review methods, inclusion of all languages, use of the GRADE approach (7), consideration of indirect evidence, and use of different streams of evidence are strengths of our urgent review. We also retrieved a total of 660 guidelines, of which 9 focused on COVID-19 (Table 3) (88-96). Of note, HFNC is not recommended by NHS England, although it is recommended by the other guideline bodies. Besides the Australian and New Zealand Guideline bodies and the American Association for Respiratory Care, most guideline bodies recommend CPAP conditionally in selected patients.

Our study has limitations. The included original studies had poor reporting quality and were mostly observational, with inappropriate control for confounding or selection bias or with only single arms. The sole adjusted study of NIV in patients with COVID-19 was imprecise and included an inappropriately large number of variables in the regression model to produce reliable results. Furthermore, studies had mixed approaches to using NIV. In some, IMV was unavailable, and in others, IMV was used when NIV failed, which can introduce severe selection bias. Although we identified many studies in COVID-19, the most robust studies were in patients with MERS or SARS.

In stream 3, the 6 identified mechanistic and laboratory studies of the risk for transmission from AGPs did not allow quantitative risk estimates. In stream 4, we noted, similarly to the CADTH review (2), a risk of bias related to confounding due to use of $\mathrm{PPE}$, which investigators often did not adjust for $(74,79,97,98)$. 


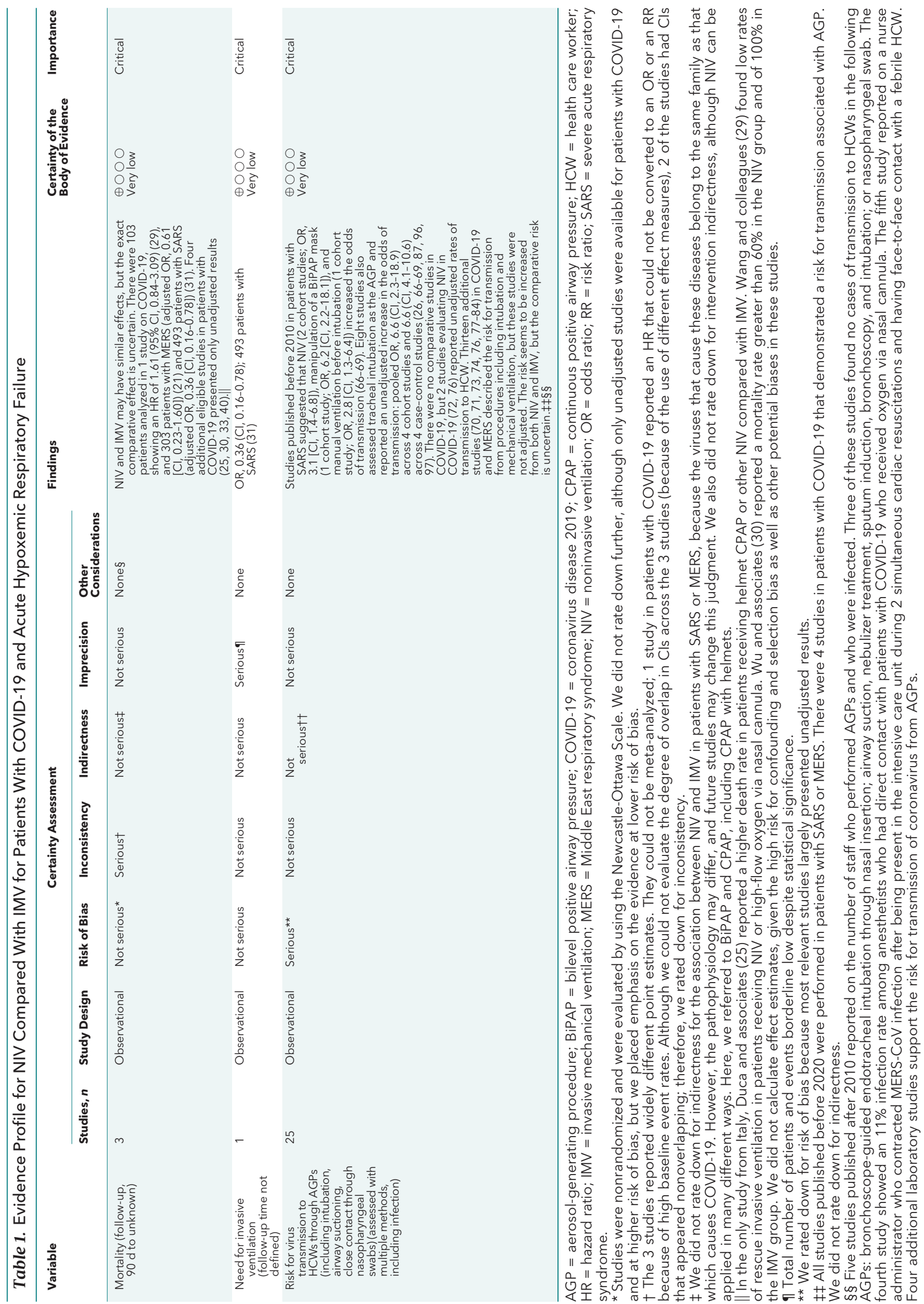




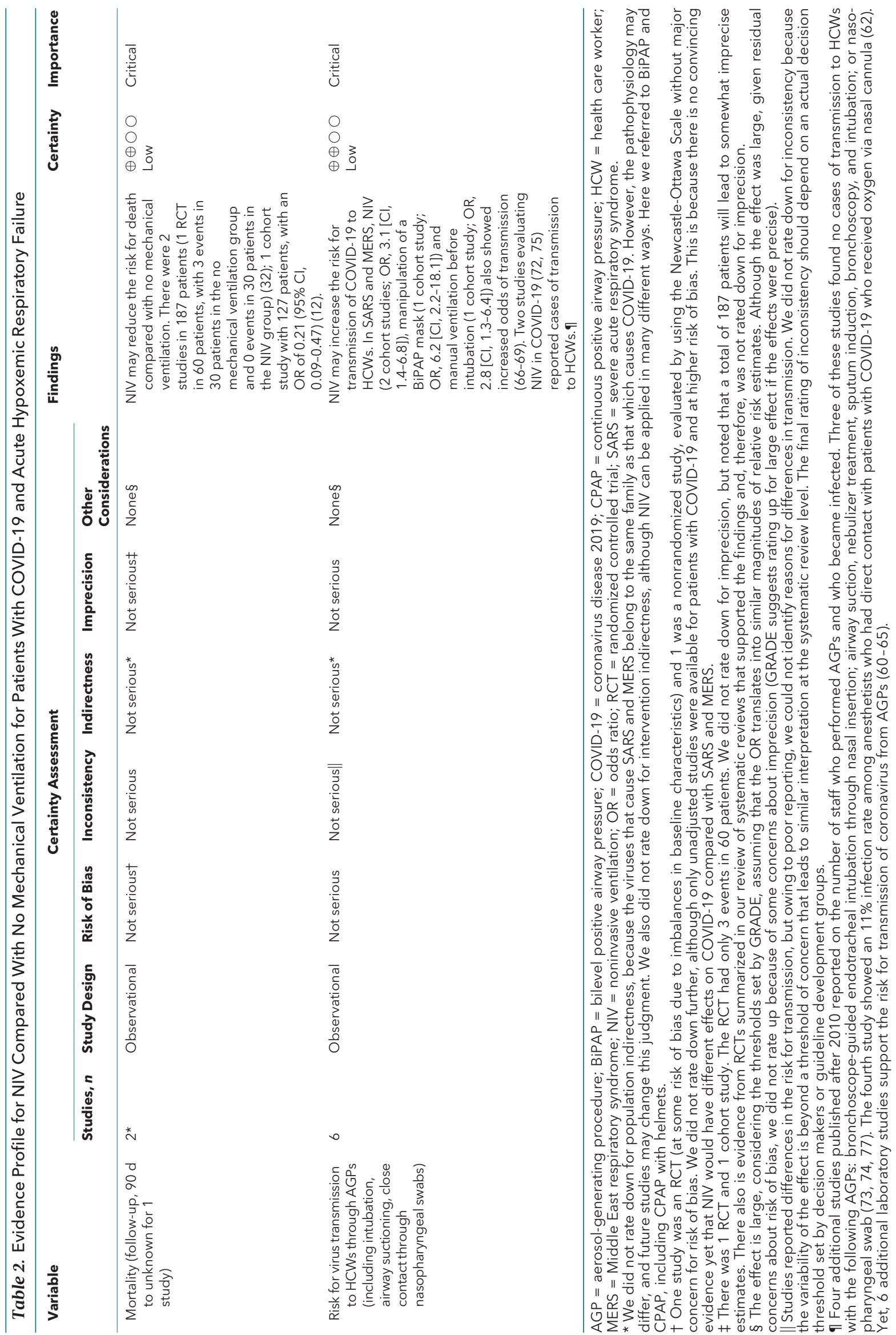




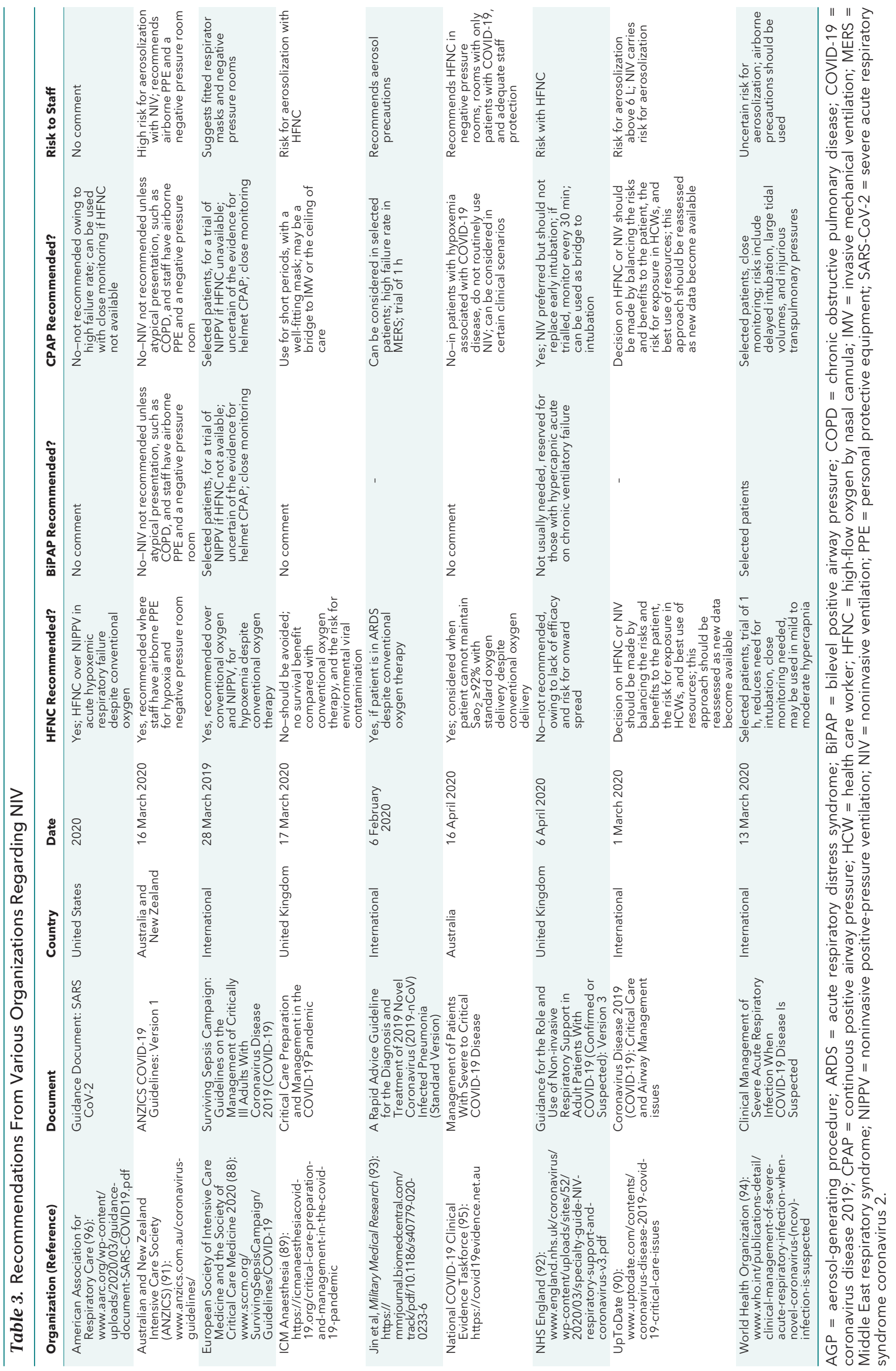


Although our data are largely observational (with the exception of 1 small RCT in patients with SARS) and the degree of indirectness still needs to be determined on the basis of new evidence emerging about the similarities of SARS, MERS, and COVID-19, prior systematic reviews could not evaluate the effect of NIV on important outcomes in patients infected with coronaviruses. At a minimum, our review serves as a snapshot of the best available evidence. Clinicians should consider using NIV only when appropriate PPE is available to protect HCWs from the infection.

It is important that researchers performing observational studies adhere to reporting standards, even during pandemics. What is needed to protect HCWs and prepare for the next pandemic are robust, wellreported studies on strategies to improve the outcomes of patients and protect those who care for them. Although pharmacotherapeutics and vaccines are in the limelight, simple process-of-care measures and common support strategies must be systematically documented and analyzed to adequately prepare for the future. Better studies are needed to inform practice guidelines and reduce inconsistency among their recommendations (ongoing studies are listed in Supplement 14, available at Annals.org).

In conclusion, our systematic review examined different streams of evidence, including original human studies evaluating different modalities of NIV, IMV, and HFNC in COVID-19, SARS, and MERS; systematic reviews in other populations; mechanistic and laboratory evidence; and studies of AGPs. We found low-certainty evidence that NIV may have similar effects as IMV but reduce mortality compared with no IMV in patients with COVID-19 (stream 1). Evidence in other populations with acute hypoxic respiratory failure suggests that NIV improves outcomes compared with conventional oxygen therapy and HFNC (stream 2). However, that evidence is indirect and very limited in children. We searched for but did not identify well-done mechanistic and other laboratory studies that allow quantification of virus transmission risk (stream 3). However, evidence in stream 4 suggests an increased risk for transmission of coronaviruses with invasive procedures, such as intubation and NIV, but also that risk for transmission was difficult to quantify exactly. On the basis of this and other reviews, PPE may reduce for some the risk for transmission during AGPs, but it will not abolish it. The poor quality of conduct and reporting of studies on the effects of NIV on important outcomes in COVID-19 is striking.

From McMaster University, Hamilton, Ontario, Canada (H.J.S., K.S., R.B., A.D., A.H., A.B., C.A.C., F.S., G.P.M., J.B., J.S., L.H., M.J., N.S., R.N., R.S., T.L., T.B., T.P., Y.Z., B.R., D.P., M.L., W.A., D.K.C.); American University of Beirut Medical Center, Beirut, Lebanon (J.K., A.E., F.C., L.H., R.E., S.Y., Z.S., I.B.A., E.A.A.); University of Hull, Hull, United Kingdom (A.M.K.); Evidence Prime, Krakow, Poland (A.B., E.B.); German Hospital of Buenos Aires, Buenos Aires, Argentina (A.I.); Guangzhou University of Chinese Medicine, Guangzhou, China (C.C.); Vita Salute San Raffaele University, Milan, Italy (G.E.M.); Beijing University of
Chinese Medicine, Beijing, China (G.C.); Institute of Acupuncture and Moxibustion, China Academy of Chinese Medical Sciences, Beijing, China (H.Z.); McMaster University, Hamilton, Ontario, Canada, and Pontificia Universidad Católica de Chile, Santiago, Chile (I.N.); London School of Hygiene and Tropical Medicine, London, United Kingdom (M.R.); Liverpool School of Tropical Medicine, Liverpool, United Kingdom (R.T., P.G.); Toronto General Hospital, Toronto, Ontario, Canada (E.F.); University of Essen, Essen, Germany (F.S.); Liverpool University Hospitals NHS Trust, Liverpool, United Kingdom (S.A.); and Jagiellonian University Medical College, Krakow, Poland (W.S.).

Disclaimer: This systematic review was commissioned and in part paid for by the World Health Organization. The authors alone are responsible for the views expressed in this article and they do not necessarily represent the decisions, policy, or views of the World Health Organization.

Acknowledgment: The authors thank Dr. Susan Norris, Science Division, WHO, for input on the protocol and sharing of information; Dr. Xuan Yu and Dr. Yuqing (Madison) Zhang for assistance with Chinese literature support; and Ms. Neera Bhatnagar, information specialist, for peer reviewing the search strategy.

Financial Support: By the World Health Organization, which commissioned this review on 3 April 2020.

Disclosures: Disclosures can be viewed at www.acponline.org /authors/icmje/ConflictOflnterestForms.do?msNum=M20-2306.

Reproducible Research Statement: Study protocol: Available from Dr. Schünemann (e-mail, schuneh@mcmaster.ca) and on PROSPERO (CRD42020178187). Statistical code: Not applicable. Data set: Will be made available at www.nornesk.no /forskningskart/NIPH_mainMap.html.

Corresponding Authors: Holger J. Schünemann, MD, PhD, MSc, Michael G. DeGroote Cochrane Canada and McMaster GRADE Centres, McMaster University, HSC-2C, 1280 Main Street West, Hamilton, Ontario L8N 3Z5, Canada (e-mail, schuneh@mcmaster.ca), and Elie A. Akl, MD, MPH, PhD, Clinical Research Institute and AUB GRADE Center, American University of Beirut, P.O. Box 11-0236/CRI (E15), Riad-El-Solh Beirut, 11072020 Beirut, Lebanon (e-mail, ea32@aub.edu.lb).

Correction: This article was corrected on 18 June 2020 to correct a label on the $\mathrm{x}$-axis in Figure 2 and to revise the citation information for reference 32.

Current author addresses and author contributions are available at Annals.org.

\section{References}

1. Coronavirus cases. Worldometer. Accessed at www.worldometers info/coronavirus/ on 18 May 2020.

2. Tran K, Cimon K, Severn M, et al. Aerosol generating procedures and risk of transmission of acute respiratory infections to healthcare workers: a systematic review. PLoS One. 2012;7:e35797. [PMID: 22563403] doi:10.1371/journal.pone.0035797 
3. Gattinoni L, Coppola S, Cressoni M, et al. COVID-19 does not lead to a "typical" acute respiratory distress syndrome [Letter]. Am J Respir Crit Care Med. 2020;201:1299-1300. [PMID: 32228035] doi:10 .1164/rccm.202003-0817LE

4. Gattinoni L, Chiumello D, Rossi S. COVID-19 pneumonia: ARDS or not? [Editorial]. Crit Care. 2020;24:154. [PMID: 32299472] doi:10 $.1186 / \mathrm{s} 13054-020-02880-z$

5. Schünemann HJ, Moja L. Reviews: rapid! rapid! rapid! ... and systematic [Editorial]. Syst Rev. 2015;4:4. [PMID: 25589399] doi:10 .1186/2046-4053-4-4

6. Higgins JP, Thomas J, Chandler J, et al, eds. Cochrane Handbook for Systematic Reviews of Interventions. Version 6.0. Wiley-Blackwell; 2019.

7. Guyatt GH, Oxman AD, Vist GE, et al. GRADE: an emerging consensus on rating quality of evidence and strength of recommendations. BMJ. 2008;336:924-6. [PMID: 18436948] doi:10.1136/bmj 39489.470347.AD

8. Atkins D, Best D, Briss PA, et al. Grading quality of evidence and strength of recommendations. BMJ. 2004;328:1490. [PMID: 15205295] doi:10.1136/bmj.328.7454.1490

9. Moher D, Liberati A, Tetzlaff J, et al. Preferred reporting items for systematic reviews and meta-analyses: the PRISMA statement. J Clin Epidemiol. 2009;62:1006-12. [PMID: 19631508] doi:10.1016/j .jclinepi.2009.06.005

10. Moskalewicz A, Oremus M. No clear choice between NewcastleOttawa Scale and Appraisal Tool for Cross-Sectional Studies to assess methodological quality in cross-sectional studies of healthrelated quality of life and breast cancer. J Clin Epidemiol. 2020;120: 94-103. [PMID: 31866469] doi:10.1016/j.jclinepi.2019.12.013

11. Wells G, Shea S, O'Connell D, et al. The Newcastle-Ottawa Scale (NOS) for assessing the quality of nonrandomised studies in metaanalyses. Ottawa Hospital. 2009. Accessed at www.ohri.ca/programs /clinical_epidemiology/oxford.asp on 11 May 2020.

12. Xu $Y$, Jiang $M, X i a o ~ Z$. Retrospective analysis of non-invasive ventilation assisted treatment of severe acute respiratory syndrome and acute respiratory failure. Chinese Journal of Respiratory and Critical Care Medicine. 2010;9:575-9.

13. Shea BJ, Reeves BC, Wells G, et al. AMSTAR 2: a critical appraisal tool for systematic reviews that include randomised or nonrandomised studies of healthcare interventions, or both. BMJ. 2017; 358:j4008. [PMID: 28935701] doi:10.1136/bmj.j4008

14. Murad MH, Mustafa RA, Schünemann $\mathrm{HJ}$, et al. Rating the certainty in evidence in the absence of a single estimate of effect. Evid Based Med. 2017;22:85-87. [PMID: 28320705] doi:10.1136/ebmed2017-110668

15. Thayer KA, Schünemann HJ. Using GRADE to respond to health questions with different levels of urgency. Environ Int. 2016;92-93: 585-9. [PMID: 27126781] doi:10.1016/j.envint.2016.03.027

16. Guyatt G, Oxman AD, Akl EA, et al. GRADE guidelines: 1. Introduction-GRADE evidence profiles and summary of findings tables. J Clin Epidemiol. 2011;64:383-94. [PMID: 21195583] doi:10 .1016/j.jclinepi.2010.04.026

17. Guyatt GH, Thorlund K, Oxman AD, et al. GRADE guidelines: 13. Preparing summary of findings tables and evidence profilescontinuous outcomes. J Clin Epidemiol. 2013;66:173-83. [PMID: 23116689] doi:10.1016/j.jclinepi.2012.08.001

18. Santesso N, Carrasco-Labra A, Langendam M, et al. Improving GRADE evidence tables part 3: detailed guidance for explanatory footnotes supports creating and understanding GRADE certainty in the evidence judgments. J Clin Epidemiol. 2016;74:28-39. [PMID: 26796947] doi:10.1016/j.jclinepi.2015.12.006

19. Santesso N, Glenton C, Dahm P, et al; GRADE Working Group. GRADE guidelines 26: informative statements to communicate the findings of systematic reviews of interventions. J Clin Epidemiol. 2020;119:126-135. [PMID: 31711912] doi:10.1016/j.jclinepi.2019.10 .014

20. Garner P, Hopewell S, Chandler J, et al; Panel for updating guidance for systematic reviews (PUGs). When and how to update systematic reviews: consensus and checklist. BMJ. 2016;354:i3507. [PMID: 27443385] doi:10.1136/bmj.i3507
21. Alraddadi BM, Qushmaq I, Al-Hameed FM, et al; Saudi Critical Care Trials Group. Noninvasive ventilation in critically ill patients with the Middle East respiratory syndrome. Influenza Other Respir Viruses. 2019;13:382-390. [PMID: 30884185] doi:10.1111/irv.12635

22. Booth CM, Matukas LM, Tomlinson GA, et al. Clinical features and short-term outcomes of 144 patients with SARS in the greater Toronto area. JAMA. 2003;289:2801-9. [PMID: 12734147]

23. Chiang $\mathrm{CH}$, Shih JF, Su WJ, et al. Eight-month prospective study of 14 patients with hospital-acquired severe acute respiratory syndrome. Mayo Clin Proc. 2004;79:1372-9. [PMID: 15544014]

24. Choi WS, Kang Cl, Kim Y, et al; Korean Society of Infectious Diseases. Clinical presentation and outcomes of Middle East respiratory syndrome in the Republic of Korea. Infect Chemother. 2016; 48:118-26. [PMID: 27433382] doi:10.3947/ic.2016.48.2.118

25. Duca A, Memaj I, Zanardi F, et al. Severity of respiratory failure and outcome of patients needing a ventilatory support in the emergency department during Italian novel coronavirus SARS-CoV-2 outbreak: preliminary data on the role of helmet CPAP and non-invasive ventilation. Preprints With the Lancet. SSRN. Preprint posted online 9 April 2020. doi:10.2139/ssrn.3566170

26. Fowler RA, Guest CB, Lapinsky SE, et al. Transmission of severe acute respiratory syndrome during intubation and mechanical ventilation. Am J Respir Crit Care Med. 2004;169:1198-202. [PMID: 14990393]

27. Li TS, Gomersall CD, Joynt GM, et al. Long-term outcome of acute respiratory distress syndrome caused by severe acute respiratory syndrome (SARS): an observational study. J Physiol. 2007;580(Pt 1):285-300. doi: 10.1113/jphysiol.2006.125336

28. Liao X, Chen H, Wang B, et al. Critical care for severe COVID-19: a population-based study from a province with low case-fatality rate in China. medRxiv. Preprint posted online 27 March 2020. doi:10 .1101/2020.03.22.20041277

29. Wang K, Zhao W, Li J, et al. The experience of high-flow nasal cannula in hospitalized patients with 2019 novel coronavirusinfected pneumonia in two hospitals of Chongqing, China. Ann Intensive Care. 2020;10:37. [PMID: 32232685] doi:10.1186 /s13613-020-00653-z

30. Wu C, Chen X, Cai Y, et al. Risk factors associated with acute respiratory distress syndrome and death in patients with coronavirus disease 2019 pneumonia in Wuhan, China. JAMA Intern Med. 2020. [PMID: 32167524] doi:10.1001/jamainternmed.2020.0994

31. Yam LY, Chan AY, Cheung TM, et al; Hong Kong Hospital Authority SARS Collaborative Group (HASCOG). Non-invasive versus invasive mechanical ventilation for respiratory failure in severe acute respiratory syndrome. Chin Med J (Engl). 2005;118:1413-21. [PMID: 16157043]

32. Qiangui L, Li F, Bing $L$, et al. Observation of the effect of early mechanical ventilation in reducing hormone dosage in SARS patients. Chinese Critical Care Medicine. 2004;16.

33. Auld S, Caridi-Scheible M, Blum JM, et al. ICU and ventilator mortality among critically ill adults with COVID-19. medRxiv. Preprint posted online 26 April 2020. doi:10.1101/2020.04.23.20076737

34. Guo J, Jiang R, Liu Z. Clinical analysis of 46 grave patients with severe acute respiratory syndrome. Zhongguo Linchuang Yisheng. 2003;31.

35. He Y, Lu Q, Guo L, et al. Application of standardized respiratory support technology in severe patients with new coronavirus pneumonia. Practical Hospital Clinical Journal. 2020;17:59-61.

36. Hua DD, Zhu D, Gao Q, et al. Clinical application of nasal highflow catheter wet oxygen therapy in the treatment of common type COVID-19. Journal of Practical Medicine. 2020:1-3.

37. Li H, Li M, Huang J, et al. Clinical analysis of 102 severe SARS patients in Shanxi Province. Journal of Shanxi Medical University. 2003;34.

38. Liu H, Shi Y. Analysis of risk factors of death in 12 SARS patients. Critical Care Medicine in China. 2003;15.

39. Liu X, Xu Y, Hu M, et al. Epidemiological characteristics and clinical characteristics of 47 cases of death of new coronavirus pneumonia in Huoshenshan Hospital. People's Liberation Army Medical Journal. 2020. 
40. Liu X, Lu J, Zhang X, et al. Nursing care of 32 patients with severe novel coronavirus pneumonia. Journal of Nurse Training. 2020:1-4. 41. Mo X, Peng P, Peng $H$, et al. Comparison of nasal high-flow humidified oxygen therapy and traditional oxygen therapy in patients with severe new coronavirus pneumonia. Guangdong Medicine. 2020:1-5.

42. Wang K. 220 cases of mechanical ventilation in the treatment of atypical pneumonia. Journal of Clinical Anesthesiology. 2004;20.

43. Wang K, Zhang Z, Yu M, et al. 15-day mortality and associated risk factors for hospitalized patients with COVID-19 in Wuhan, China: an ambispective observational cohort study [Letter]. Intensive Care Med. 2020. [PMID: 32328724] doi:10.1007/s00134-020-06047-w

44. Yang Z, Peng B, Zhang Y, et al. Analysis of 63 SARS critical cases. Armed Police Medicine. 2003:563-4.

45. Yang L. Analysis of complications of noninvasive positive pressure ventilation in SARS critical patients and discussion of respiratory therapy. Critical Care Medicine in China. 2004;16.

46. Yu L, Huang J, Zhou S. Analysis report on 167 SARS patients admitted to Beijing Youan Hospital [Abstract]. Conference Proceedings, Hangzhou, Zhejiang, China; 2003. Abstract 4.

47. Zheng Z, Chen R, Li Y, et al. The effect and influencing factors of noninvasive ventilation in the treatment of ARDS in SARS. Journal of Guangzhou Medical College. 2004;21-3.

48. Berbenetz N, Wang Y, Brown J, et al. Non-invasive positive pressure ventilation (CPAP or bilevel NPPV) for cardiogenic pulmonary oedema. Cochrane Database Syst Rev. 2019;4:CD005351. [PMID: 30950507] doi:10.1002/14651858.CD005351.pub4

49. Bharadwaj SK, Alonazi A, Banfield L, et al. Bubble versus other continuous positive airway pressure forms: a systematic review and meta-analysis. Arch Dis Child Fetal Neonatal Ed. 2020. [PMID: 31969457] doi:10.1136/archdischild-2019-318165

50. Jat KR, Mathew JL. Continuous positive airway pressure (CPAP) for acute bronchiolitis in children. Cochrane Database Syst Rev. 2019;1:CD010473. [PMID: 30701528] doi:10.1002/ 14651858.CD010473.pub3

51. Ni YN, Luo J, Yu H, et al. The effect of high-flow nasal cannula in reducing the mortality and the rate of endotracheal intubation when used before mechanical ventilation compared with conventional oxygen therapy and noninvasive positive pressure ventilation: a systematic review and meta-analysis. Am J Emerg Med. 2018;36:226233. [PMID: 28780231] doi:10.1016/j.ajem.2017.07.083

52. Ni YN, Luo J, Yu H, et al. Can high-flow nasal cannula reduce the rate of endotracheal intubation in adult patients with acute respiratory failure compared with conventional oxygen therapy and noninvasive positive pressure ventilation? A systematic review and metaanalysis. Chest. 2017;151:764-775. [PMID: 28089816] doi:10.1016/j .chest.2017.01.004

53. Xiu-Ping $X$, Shu-Ling $H$, Jing-Yuan $X$, et al. Noninvasive ventilation in acute hypoxemic nonhypercapnic respiratory failure: a systematic review and meta-analysis. Crit Care Med. 2017;45:e727-33. [PMID: 28441237] doi:10.1097/CCM.0000000000002361

54. Zheng X, Qu NN, Wang WP, et al. Meta-analysis of the effects of helmet-assisted non-invasive ventilation in the treatment of acute respiratory failure. Eur Rev Med Pharmacol Sci. 2019;23:4382-4390. [PMID: 31173312] doi:10.26355/eurrev_201905_17945

55. Bocchile RL, Cazati DC, Timenetsky KT, et al. The effects of highflow nasal cannula on intubation and re-intubation in critically ill patients: a systematic review, meta-analysis and trial sequential analysis. Cochrane Database Syst Rev. 2019;1:CD011231. (doi):10.1002/ 14651858.CD011231.pub2.

56. Huiying Z, Huixia W, Feng S, et al. High-flow nasal cannula oxygen therapy is superior to conventional oxygen therapy but not to noninvasive mechanical ventilation on intubation rate: a systematic review and meta-analysis. Crit Care. 2017;21:1-12. [PMID: 28701227] doi:10.1186/s13054-017-1760-8

57. Ou X, Hua Y, Liu J, et al. Effect of high-flow nasal cannula oxygen therapy in adults with acute hypoxemic respiratory failure: a metaanalysis of randomized controlled trials. CMAJ. 2017;189:E260E267. [PMID: 28246239] doi:10.1503/cmaj.160570
58. Rochwerg B, Granton D, Wang DX, et al. High flow nasal cannula compared with conventional oxygen therapy for acute hypoxemic respiratory failure: a systematic review and meta-analysis. Intensive Care Med. 2019;45:563-572. [PMID: 30888444] doi:10.1007/s00134 -019-05590-5

59. Luo J, Duke T, Chisti MJ, et al. Efficacy of high-flow nasal cannula vs standard oxygen therapy or nasal continuous positive airway pressure in children with respiratory distress: a meta-analysis. J Pediatr. 2019;215:199-208.e8. [PMID: 31570155] doi:10.1016/j.jpeds.2019 .07 .059

60. Adhikari U, Chabrelie A, Weir M, et al. A case study evaluating the risk of infection from Middle Eastern respiratory syndrome coronavirus (MERS-CoV) in a hospital setting through bioaerosols. Risk Anal. 2019;39:2608-2624. [PMID: 31524301] doi:10.1111/risa .13389

61. Pyankov OV, Bodnev SA, Pyankova OG, et al. Survival of aerosolized coronavirus in the ambient air. J Aerosol Sci. 2018;115:158163. [PMID: 32226116] doi:10.1016/j.jaerosci.2017.09.009

62. Wan GH, Tsai YH, Wu YK, et al. A large-volume nebulizer would not be an infectious source for severe acute respiratory syndrome. Infect Control Hosp Epidemiol. 2004;25:1113-5. [PMID: 15636302] 63. Bae S, Kim MC, Kim JY, et al. Effectiveness of surgical and cotton masks in blocking SARS-CoV-2: a controlled comparison in 4 patients. Ann Intern Med. 2020. [PMID: 32251511] doi:10.7326/M201342

64. Fears A, Klimstra W, Duprex P, et al. Comparative dynamic aerosol efficiencies of three emergent coronaviruses and the unusual persistence of SARS-CoV-2 in aerosol suspensions. medRxiv. Preprint posted online 13 April 2020. doi:10.1101/2020.04.13 .20063784

65. Guo ZD, Wang ZY, Zhang SF, et al. Aerosol and surface distribution of severe acute respiratory syndrome coronavirus 2 in hospital wards, Wuhan, China, 2020. Emerg Infect Dis. 2020;26. [PMID: 32275497] doi:10.3201/eid2607.200885

66. Chen WQ, Ling WH, Lu CY, et al. Which preventive measures might protect health care workers from SARS? BMC Public Health. 2009;9:81. [PMID: 19284644] doi:10.1186/1471-2458-9-81

67. Pei LY, Gao ZC, Yang Z, et al. Investigation of the influencing factors on severe acute respiratory syndrome among health care workers. Beijing Da Xue Xue Bao Yi Xue Ban. 2006;38:271-5. [PMID: 16778970]

68. Raboud J, Shigayeva A, McGeer A, et al. Risk factors for SARS transmission from patients requiring intubation: a multicentre investigation in Toronto, Canada. PLoS One. 2010;5:e10717. [PMID: 20502660] doi:10.1371/journal.pone.0010717

69. Liu W, Tang F, Fang LQ, et al. Risk factors for SARS infection among hospital healthcare workers in Beijing: a case control study. Trop Med Int Health. 2009;14:52-9. doi:10.1111/j.1365-3156.2009 $.02255 . x$

70. Cai SJ, Wu LL, Chen DF, et al. [Analysis of bronchoscope-guided tracheal intubation in 12 cases with coronavirus disease 2019 under the personal protective equipment with positive pressure protective hood]. Zhonghua Jie He He Hu Xi Za Zhi. 2020;43:332-334. [PMID: 32133829] doi:10.3760/cma.j.cn112147-20200222-00153

71. Angel L, Kon ZN, Chang SH, et al. Novel percutaneous tracheostomy for critically ill patients with COVID-19. Ann Thorac Surg. 2020. [PMID: 32339508] doi:10.1016/j.athoracsur.2020.04.010

72. Ng K, Poon BH, Kiat Puar TH, et al. COVID-19 and the risk to health care workers: a case report. Ann Intern Med. 2020. [PMID: 32176257] doi:10.7326/L20-0175

73. Buchholz U, Müller MA, Nitsche A, et al. Contact investigation of a case of human novel coronavirus infection treated in a German hospital, October-November 2012. Euro Surveill. 2013;18. [PMID: 23449231]

74. Folgueira MD, Munoz-Ruiperez C, Alonso-Lopez MA, et al. SARS-CoV-2 infection in health care workers in a large public hospital in Madrid, Spain, during March 2020. medRxiv. Preprint posted online 27 April 2020. doi:10.1101/2020.04.07 .20055723 
75. Heinzerling A, Stuckey MJ, Scheuer T, et al. Transmission of COVID-19 to health care personnel during exposures to a hospitalized patient - Solano County, California, February 2020. MMWR Morb Mortal Wkly Rep. 2020;69:472-476. [PMID: 32298249] doi:10 .15585/mmwr.mm6915e5

76. Zhong Q, Liu YY, Luo Q, et al. Spinal anaesthesia for patients with coronavirus disease 2019 and possible transmission rates in anaesthetists: retrospective, single-centre, observational cohort study. $\mathrm{Br} \mathrm{J}$ Anaesth. 2020;124:670-675. [PMID: 32234250] doi:10.1016/j.bja .2020.03.007

77. Hall AJ, Tokars JI, Badreddine SA, et al. Health care worker contact with MERS patient, Saudi Arabia. Emerg Infect Dis. 2014;20: 2148-51. [PMID: 25418612] doi:10.3201/eid2012.141211

78. Alraddadi BM, Al-Salmi HS, Jacobs-Slifka K, et al. Risk factors for Middle East respiratory syndrome coronavirus infection among healthcare personnel. Emerg Infect Dis. 2016;22:1915-1920. [PMID: 27767011] doi:10.3201/eid2211.160920

79. Assiri A, McGeer A, Perl TM, et al; KSA MERS-CoV Investigation Team. Hospital outbreak of Middle East respiratory syndrome coronavirus. N Engl J Med. 2013;369:407-16. [PMID: 23782161] doi:10 .1056/NEJMoa1306742

80. Nam HS, Yeon MY, Park JW, et al. Healthcare worker infected with Middle East respiratory syndrome during cardiopulmonary resuscitation in Korea, 2015. Epidemiol Health. 2017;39:e2017052. [PMID: 29129042] doi:10.4178/epih.e2017052

81. Amer H, Alqahtani AS, Alaklobi F, et al. Healthcare worker exposure to Middle East respiratory syndrome coronavirus (MERS-CoV): revision of screening strategies urgently needed. Int J Infect Dis. 2018;71:113-116. [PMID: 29649550] doi:10.1016/j.ijid.2018.04.001 82. Alanazi KH, Killerby ME, Biggs HM, et al. Scope and extent of healthcare-associated Middle East respiratory syndrome coronavirus transmission during two contemporaneous outbreaks in Riyadh, Saudi Arabia, 2017. Infect Control Hosp Epidemiol. 2019;40:79-88. [PMID: 30595141] doi:10.1017/ice.2018.290

83. Hunter JC, Nguyen D, Aden B, et al. Transmission of Middle East respiratory syndrome coronavirus infections in healthcare settings, Abu Dhabi. Emerg Infect Dis. 2016;22:647-56. [PMID: 26981708] doi: 10.3201/eid2204.151615

84. Memish ZA, Zumla Al, Assiri A. Middle East respiratory syndrome coronavirus infections in health care workers [Letter]. N Engl J Med. 2013;369:884-6. [PMID: 23923992] doi:10.1056/NEJMc1308698

85. Patel BK, Wolfe KS, Pohlman AS, et al. Effect of noninvasive ventilation delivered by helmet vs face mask on the rate of endotracheal intubation in patients with acute respiratory distress syndrome: a randomized clinical trial. JAMA. 2016;315:2435-41. [PMID: 27179847] doi:10.1001/jama.2016.6338

86. Chidini G, Piastra M, Marchesi T, et al. Continuous positive airway pressure with helmet versus mask in infants with bronchiolitis: an RCT. Pediatrics. 2015;135:e868-75. [PMID: 25780074] doi:10.1542 /peds.2014-1142

87. Loeb M, McGeer A, Henry B, et al. SARS among critical care nurses, Toronto. Emerg Infect Dis. 2004;10:251-5. [PMID: 15030692]
88. Alhazzani W, Møller MH, Arabi YM, et al. Surviving Sepsis Campaign: guidelines on the management of critically ill adults with coronavirus disease 2019 (COVID-19). Intensive Care Med. 2020;46:854 887. [PMID: 32222812] doi:10.1007/s00134-020-06022-5

89. ICM Anaesthesia. Critical care preparation and management in the COVID-19 pandemic. 17 March 2020. Accessed at https://icmanaesthesiacovid-19.org/critical-care-preparation-and -management-in-the-covid-19-pandemic on 20 April 2020.

90. Anesi GL. Coronavirus disease 2019 (COVID-19): critical care and airway management issues. In: Manaker S, Finlay G, Bloom A, eds. UpToDate. 1 March 2020. Accessed at www uptodate.com/contents/coronavirus-disease-2019-covid-19-critical -care-and-airway-management-issues on 11 May 2020.

91. Australian and New Zealand Intensive Care Society (ANZICS). ANZICS COVID-19 guidelines. Version 1. 16 March 2020. Accessed at www.anzics.com.au/coronavirus-guidelines/ on 15 April 2020.

92. National Health Service. Guidance for the role and use of noninvasive respiratory support in adult patients with COVID-19 (confirmed or suspected). 2020. Accessed at www.england.nhs .uk/coronavirus/wp-content/uploads/sites/52/2020/03/specialty-guide-NIV-respiratory-support-and-coronavirus-v3.pdf on 15 April 2020.

93. Jin YH, Cai L, Cheng ZS, et al; for the Zhongnan Hospital of Wuhan University Novel Coronavirus Management and Research Team, Evidence-Based Medicine Chapter of China International Exchange and Promotive Association for Medical and Health Care (CPAM). A rapid advice guideline for the diagnosis and treatment of 2019 novel coronavirus (2019-nCoV) infected pneumonia (standard version). Mil Med Res. 2020;7:4. [PMID: 32029004] doi:10 .1186/s40779-020-0233-6

94. World Health Organization. Clinical management of severe acute respiratory infection when COVID-19 disease is suspected. 13 March 2020. Accessed at www.who.int/publications-detail/clinical -management-of-severe-acute-respiratory-infection-when-novel -coronavirus-(ncov)-infection-is-suspected on 18 May 2020.

95. taskforce NCCe. Management of patients with severe to critical COVID-19 disease. 2020. Accessed at https://covid19evidence.net .au/wp-content/uploads/2020/04/NATIONAL-COVID-19_TASK FORCE_FLOW-CHART_2_SEVERE-CRITICAL_v2.0_16.4.2020.pdf on 15 April 2020.

96. American Association for Respiratory Care. Accessed at www .aarc.org/wp-content/uploads/2020/03/guidance-document-SARS -COVID19.pdf on 15 April 2020.

97. Teleman MD, Boudville IC, Heng BH, et al. Factors associated with transmission of severe acute respiratory syndrome among health-care workers in Singapore. Epidemiol Infect. 2004;132:797803. [PMID: 15473141]

98. Scales DC, Green K, Chan AK, et al. Illness in intensive care staff after brief exposure to severe acute respiratory syndrome. Emerg Infect Dis. 2003;9:1205-10. [PMID: 14609453] 
Current Author Addresses: Drs. H. Schünemann, BrignardelloPetersen, Darzi, Bognanni, Cuello-Garcia, F. Schünemann, Brozek, Schmidt, Junek, Nieuwlaat, Piggott, Zhang, Rochwerg, Perri, Loeb, Alhazzani, and Chu; Ms. Solo; Ms. Hajizadeh; Mr. Morgano; Ms. Harrison; Ms. Santesso; Ms. Stalteri; Ms. Lotfi; and Mr. Baldeh: McMaster University, HSC-2C, 1280 Main Street West, Hamilton, Ontario L8N 3Z5, Canada.

Dr. Khamis: University of Hull, Cottingham Road, Hull, East Riding of Yorkshire, HU6 7RX United Kingdom.

Dr. C. Chen: Guangzhou University of Chinese Medicine, Jichang Road 12, Baiyun District, Guangzhou, Guangdong Province, China.

Ms. Khabsa, Ms. El-Harakeh, Dr. Chamseddine, Ms. Hneiny, Ms. El-Khoury, Ms. Yaacoub, Ms. Saad, Dr. Bou Akl, and Dr. Akl: American University of Beirut Medical Center, Riad-ElSolh, Beirut 1107 2020, Lebanon.

Dr. Bak and Ms. Borowiack: Evidence Prime, Torunska 5, 30 056 Krakow, Poland.

Dr. Izcovich: German Hospital of Buenos Aires, Pueyrredón 1640, Buenos Aires, C1118 AAT, Argentina.

Dr. Muti-Schünemann: Vita Salute San Raffaele University, Via Olgettina Milano, 58, 20132 Milan, Italy.

Dr. G. Chen: Beijing University of Chinese Medicine 5 HaiYunCang, XiCheng, Beijing, China.

Dr. Zhao: Institute of Acupuncture and Moxibustion, China Academy of Chinese Medical Sciences, No. 16, Nanxiaojie Street, Dongcheng District, Beijing, China.

Dr. Neumann: Pontificia Universidad Católica de Chile, Alameda 340, Santiago, Chile.

Ms. Reinap: London School of Hygiene and Tropical Medicine, Keppel St, Bloomsbury, London WC1E 7HT, United Kingdom.

Drs. Thomas and Garner: Department of Clinical Sciences, Liverpool School of Tropical Medicine, Liverpool L3 50A, United Kingdom.

Dr. Fan: Toronto General Hospital, 585 University Avenue, PMB 11-123, Toronto, Ontario, M5G 2N2, Canada.

Dr. Stehling: Klinik für Kinderheilkunde III, Abteilung für Pädiatrische Pneumologie, University of Essen, Hufelandstraße 55, 45147 Essen, Germany.

Dr. Aston: Tropical and Infectious Diseases Unit, Liverpool University Hospitals NHS Trust, Prescot Street, Liverpool L7 8XP, United Kingdom.

Dr. Szczeklik: Department of Intensive Care and Perioperative Medicine, Jagiellonian University Medical College, Krakow, Poland.
Author Contributions: Conception and design: H.J. Schünemann, J. Khabsa, K. Solo, A. Khamis, A. El-Harakeh, F. Chamseddine, N. Santesso, R. El-Khoury, S. Yaacoub, R. Thomas, Z. Saad, B. Rochwerg, I. Bou Akl, D.K. Chu, P. Garner, W. Szczeklik, E.A. Akl.

Analysis and interpretation of the data: H.J. Schünemann, J. Khabsa, K. Solo, A. Khamis, R. Brignardello-Petersen, A. ElHarakeh, A. Bak, F. Chamseddine, F. Schünemann, G.P. Morgano, I. Neumann, M. Junek, R. El-Khoury, S. Yaacoub, T. Lotfi, T. Baldeh, T. Piggott, Y. Zhang, Z. Saad, B. Rochwerg, D. Perri, E. Fan, F. Stehling, I. Bou Akl, P. Garner, S. Aston, W. Alhazzani, W. Szczeklik, D.K. Chu, E.A. Akl.

Drafting of the article: H.J. Schünemann, J. Khabsa, K. Solo, A. Khamis, C.A. Cuello-Garcia, I. Neumann, R. Nieuwlaat, T. Piggott, P. Garner.

Critical revision for important intellectual content: H.J. Schünemann, J. Khabsa, K. Solo, A. Khamis, A. El-Harakeh, C.A. Cuello-Garcia, F. Chamseddine, I. Neumann, J. Brozek, L. Harrison, N. Santesso, R. El-Khoury, R. Thomas, R. Nieuwlaat, T. Lotfi, T. Baldeh, T. Piggott, Z. Saad, B. Rochwerg, D. Perri, E. Fan, M.B. Loeb, P. Garner, S. Aston, W. Alhazzani, W. Szczeklik, D.K. Chu, E.A. Akl.

Final approval of the article: H.J. Schünemann, J. Khabsa, K. Solo, A. Khamis, R. Brignardello-Petersen, A. El-Harakeh, A. Darzi, A. Hajizadeh, A. Bognanni, A. Bak, A. Izcovich, C.A. Cuello-Garcia, C. Chen, E. Borowiack, F. Chamseddine, F. Schünemann, G.P. Morgano, G. Muti-Schünemann, G. Chen, H. Zhao, I. Neumann, J. Brozek, J.Z. Schmidt, L. Hneiny, L. Harrison, M. Reinap, M. Junek, N. Santesso, R. El-Khoury, R. Thomas, R. Nieuwlaat, R. Stalteri, S. Yaacoub, T. Lotfi, T. Baldeh, T. Piggott, Y. Zhang, Z. Saad, B. Rochwerg, D. Perri, E. Fan, F. Stehling, I. Bou Akl, M.B. Loeb, P. Garner, S. Aston, W. Alhazzani, W. Szczeklik, D.K. Chu, E.A. Akl.

Provision of study materials or patients: H.J. Schünemann, A. Bognanni, G. Muti-Schünemann.

Statistical expertise: H.J. Schünemann, A. Khamis, R. Brignardello-Petersen, D.K. Chu.

Obtaining of funding: H.J. Schünemann, E.A. Akl.

Administrative, technical, or logistic support: H.J. Schünemann, K. Solo, J. Brozek, L. Harrison, M. Junek, R. Stalteri, T. Piggott, E.A. Akl.

Collection and assembly of data: H.J. Schünemann, J. Khabsa, K. Solo, A. Khamis, R. Brignardello-Petersen, A. El-Harakeh, A. Darzi, A. Hajizadeh, A. Bognanni, A. Izcovich, C.A. CuelloGarcia, C. Chen, E. Borowiack, F. Chamseddine, F. Schünemann, G.P. Morgano, G. Muti-Schünemann, G. Chen, H. Zhao, I. Neumann, J. Brozek, J.Z. Schmidt, L. Hneiny, L. Harrison, M. Reinap, M. Junek, R. El-Khoury, R. Thomas, R. Stalteri, S. Yaacoub, T. Lotfi, T. Baldeh, T. Piggott, Y. Zhang, Z. Saad, I. Bou Akl, W. Szczeklik, D.K. Chu, E.A. Akl. 